\title{
Imperforate hymen
}

Pierluigi Marzuillo, Stefano Guarino, Andrea Apicella, Angela La Manna

Department of Woman, Child and General and Specialized Surgery, Università degli Studi della Campania "Luigi Vanvitelli" Napoli, Italy

Submitted:

27.11.2016

Accepted:

15.12.2016

Correspondence:

Pierluigi Marzuillo

E-mail:

pierluigi.marzuillo@gmail.com

(C) Copyright 2017 by Turkish Association of Urology

Available online at www.turkishjournalofurology.com
Dear Editor,

We would like to point the attention of the Readers to a condition that can be easily identified, if known, and that can prevent future complications. At genital clinical examination of a 45 days old breastfed female patient we found bulging of hymenal membrane (Figure 1) with subsequent diagnosis of imperforate hymen $(\mathrm{IH})$. The patient underwent to hymenectomy with the aim to prevent the future complications typical of IH. ${ }^{[1]}$ The IH is a rare congenital anomaly with prevalence of $0.05-0.1 \%,{ }^{[2]}$ resulting from failure of distal canalization of the vaginal plate at the junction between the urogenital sinus and the vagina. ${ }^{[2]}$ It could be an isolated anomaly but associations with genitourinary tract anomalies (e.g.; renal agenesis) or genetic disorder (e.g.; ectrodactyly) have been described. ${ }^{[1,2]}$ Imperforate hymen occludes outflow from the female genital tract and then accumulation of uterine and vaginal secretions occurs. Usually the diagnosis is made either in the newborn period or during adolescence. ${ }^{[1]}$ The newborn may present with a whitish bulging mass filling the vaginal introitus while the adolescent may present amenorrhea, cyclic abdominal pain or bluish bulging introital mass. ${ }^{[1,2]}$ The therapy is always represented by hymenectomy. ${ }^{[3]}$

It has been reported that 2 distinct subpopulations of girls with IH exist on the basis of the age at diagnosis. ${ }^{[1]}$ One group comprehends younger girls $(<3$ years old) usually asymptomatic and diagnosed accidentally through physical examination alone. ${ }^{[1]}$ The other group consists of older girls ( $>9$ years old), usually symptomatic, experiencing protracted symptoms and undergoing unnecessary laboratory

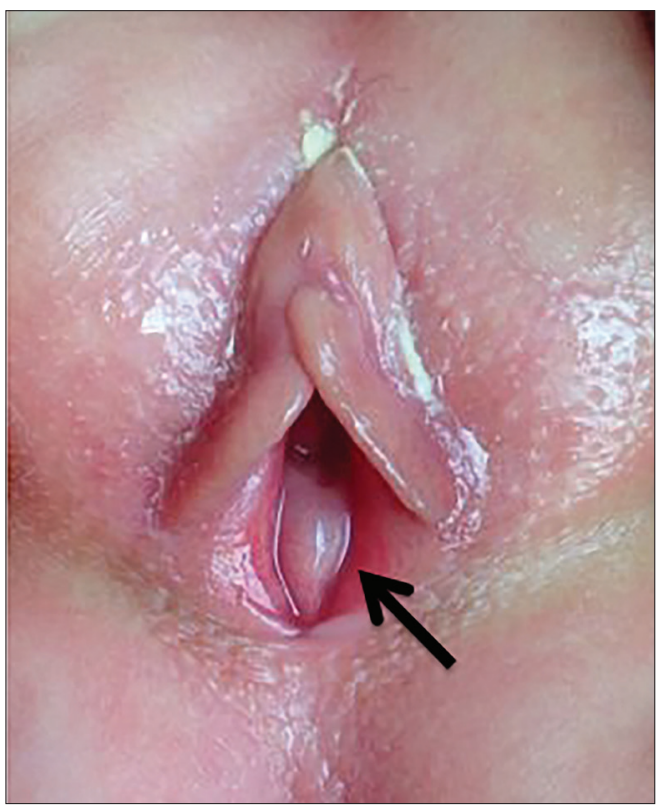

Figure 1. Imperforated hymen

The arrow indicates the imperforated hymen. It appears as bulging mass filling the vaginal introitus.

and radiographic studies without genital clinical examination for two thirds of the cases. ${ }^{[1]}$ Such as female epispadias, ${ }^{[4]}$ imperforate hymen is an "at glance" diagnosis, easily performed in the neonatal period with a simple genital clinical examination and presenting hymenal bulging as diagnostic clue. The optimal timing for the hymenectomy is not clear but a precocious IH diagnosis could avoid protracted symptoms and unnecessary laboratory and radiographic studies during the adolescence.

Informed Consent: Written informed consent was obtained from patients' parents who participated in this study.

Peer-review: Externally peer-reviewed. 
Author Contributions: Concept - P.M., S.G., A.A., A.L.M.; Design - P.M., S.G., A.A., A.L.M.; Supervision - P.M., S.G., A.A., A.L.M.; Materials - P.M., S.G., A.A., A.L.M.; Data Collection and/or Processing - P.M., S.G., A.A., A.L.M.; Analysis and/or Interpretation - P.M., S.G., A.A., A.L.M.; Literature Search - P.M., S.G., A.A., A.L.M.; Writing Manuscript - P.M., S.G., A.A., A.L.M.; Critical Review - P.M., S.G., A.A., A.L.M.

Conflict of Interest: No conflict of interest was declared by the authors.

Financial Disclosure: The authors declared that this study has received no financial support.

\section{References}

1. Posner JC, Spandorfer PR. Early detection of imperforate hymen prevents morbidity from delays in diagnosis. Pediatrics 2005;115:1008-12. [CrossRef]

2. Gearhart JP, Rink RC, Mouriquand PDE. Pediatric Urology. $2^{\text {nd }}$ ed. Elsevier-Saunders; 2009.

3. Basaran M, Usal D, Aydemir C. Hymen sparing surgery for imperforate hymen: case reports and review of literature. J Pediatr Adolesc Gynecol 2009;22:61-4. [CrossRef]

4. Apicella A, Marzuillo P, Marotta R, La Manna A. Female Epispadias. J Pediatr 2015;167:1164. [CrossRef] 